\title{
HEAT TREATMENT EFFECT ON THE STRUCTURE FORMATION OF DIRECTIONALLY SOLIDIFIED NICKEL ALLOY AFTER SLM
}

\author{
${ }^{1}$ Evgenii BORISOV, ${ }^{1}$ Kirill STARIKOV, ${ }^{1}$ Artem KIM, ${ }^{1,2}$ Vera POPOVICH, ${ }^{1}$ Anatoly POPOVICH \\ ${ }^{1}$ Peter the Great St. Petersburg Polytechnic University, St. Petersburg, Russia, evgenii.borisov@icloud.com \\ ${ }^{2}$ Faculty of Mechanical, Maritime, and Materials Engineering, Delft University of Technology, Delft, \\ The Netherlands, EU
}

https://doi.org/10.37904/metal.2021.4235

\begin{abstract}
The aim of this study was to determine the influence of heat treatment on the microstructure of single-crystal nickel-based alloy manufactured by selective laser melting with a high-temperature substrate preheating. The change of gamma/gamma prime -phases ratio was established as a result of various heat treatment modes.
\end{abstract}

Keywords: Selective laser melting, single crystal alloys, powder metallurgy, additive manufacturing

\section{INTRODUCTION}

Selective laser melting (SLM) is an additive manufacturing (AM) technology that allows the manufacture of metal products from a powder material [1]. Currently, there are many alloys available for manufacturing with this technology [2-4]. The complexity of the products' shape practically does not affect the cost of products and the duration of their manufacture. Therefore, already now this technology has found application in the medical field, where complex-shaped metal products with a developed surface are required to improve biofouling. In the aerospace industry, the SLM technology is also used to manufacture products of complex shape with internal channels and cavities [5]. The use of such products in the airframe design will reduce the weight of the aircraft [6]. In addition, it becomes possible to quickly manufacture parts upon request, if necessary, to replace them [7, 8]. In the case of using such parts in engine elements, it is possible to achieve greater fuel efficiency and less emission by creating more optimal conditions for the movement of gas flows and fuel combustion [9]. For the hot part, the most demanded material is nickel alloys. In the SLM technology, good weldability of the alloy is very important in order to obtain defect-free parts [10]. Therefore, most of the works are devoted to the study of weldable alloys, such as Inconel 718 [11-14]. However, the high-temperature strength of such alloys is lower, which limits their use to less heat-loaded areas of the engine. For use in the flame tube zone, as well as in the hot part of the turbine, it is necessary to use alloys with a high content of the intermetallic phase. However, such alloys have a much lower weldability, which leads to the formation of defects when trying to obtain high-quality products by the SLM method due to significant temperature gradients during laser heating $[15,16]$. As one of the ways to prevent the formation of defects, heating of the working platform and the parts themselves is used in the process of manufacturing the part [15-17]. It helps to reduce thermal gradients and reduce thermal stress values. However, due to the fact that these preheating temperatures can be higher than the operating temperatures of the alloy used, and the duration of the manufacturing process can be up to several hours, it is important to understand what changes occur with the alloy structure. But besides this, there is the possibility of carrying out heat treatment directly inside the SLM machine. Therefore, the purpose of this work was to study the effect of heating the working platform of the machine after the high-temperature SLM process on the structure parameters. 


\section{EXPERIMENTAL METHODS}

For the manufacture of test samples, we used a powder of a heat-resistant nickel alloy obtained by plasma atomization of a rotating electrode. Alloy is a three-phase system consisting of a nickel-based $y$-solid solution with an FCC crystal lattice, dispersion precipitates of the reinforcing $\mathrm{Y}^{\prime}$-phase based on the $\mathrm{Ni}_{3} \mathrm{Al}$ intermetallic and MC type carbides [18]. The chemical composition of the alloy is shown in Table 1.

Samples were made on the Aconity3D MIDI selective laser melting machine (Aconity3D GmbH, Germany). SLM parameters resulting in the absence of cracks were selected based on our previous study [18].The machine is equipped with laser source with variable focal spot diameter with Gauss power distribution and a maximum power 1000 watts. Moreover, machine is equipped with a module to enable operation with platform preheating up to $1200^{\circ} \mathrm{C}$.

Rectangular specimens manufactured from the nickel-based superalloy (the chemical composition is given in Table 1) were exposed to heat treatment.

Table 1Chemical composition of nickel alloy powder (wt\%)

\begin{tabular}{ccccccccccc}
\hline $\mathbf{N i}$ & $\mathbf{C r}$ & Al & Mo & W & Co & Re & Ta & Nb & C & B \\
\hline Balance & 4.9 & 5.9 & 1.1 & 8.4 & 9.0 & 1.93 & 4.1 & 1.6 & 0.12 & 0.01 \\
\hline
\end{tabular}

The heat treatment of the specimens was carried out according to the conditions: heating to $1200{ }^{\circ} \mathrm{C}$, holding for 4 hours, cooling with platform. The heat treatment conditions were selected in accordance with the maximum heating temperature of the working platform.

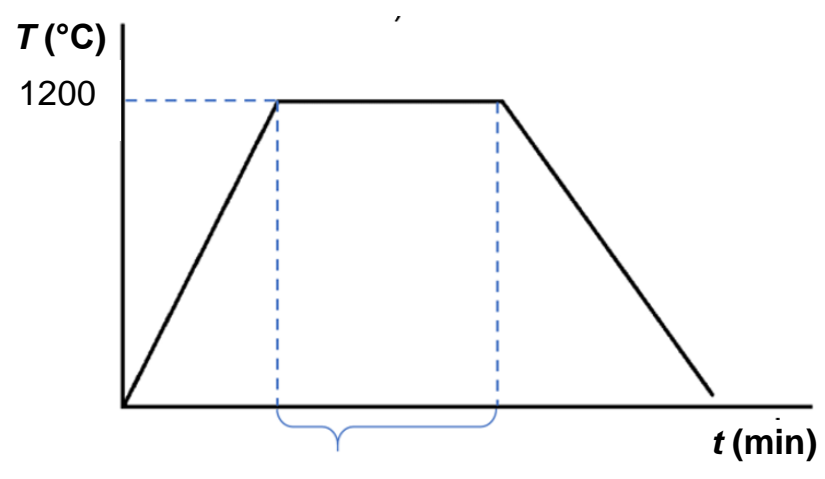

240

Figure 1Heat treatment parameters

After heat treatment specimens were cut and polished along the build direction. To highlight the microstructure specimens were etched with $\mathrm{CuSO}_{4}, \mathrm{H}_{2} \mathrm{SO}_{4}$ and $\mathrm{HCl}$. Carl Zeiss Supra 55VP scanning electron microscope was used for microstructure analysis.X-ray diffraction analysis was carried out using a diffractometer Bruker D8 Advance (CuKa $=0.15406 \mathrm{~nm})$ in the $2 \theta$-range of $30-100^{\circ}$ with a scanning step of 0.020 and exposition of $1.5 \mathrm{~s}$ at every step. Structural parameters were refined by the Rietveld method, crystal density for equiatomic alloys was calculated from the mass and lattice parameter using the TOPAS5 program.

\section{RESULTS AND DISCUSSION}

The microstructure of the obtained samples consists of elongated cells located mainly along the growing direction of the samples $\mathrm{Y}$ - solid solution with scattered particles $\mathrm{y}^{\prime}$ - phase formed on the basis of the intermetallic compound $\mathrm{Ni}_{3} \mathrm{Al}$ (Figure 2), which in turn consist of cuboid microparticles with an average size of $\sim 200$ nm (Figure 2). 


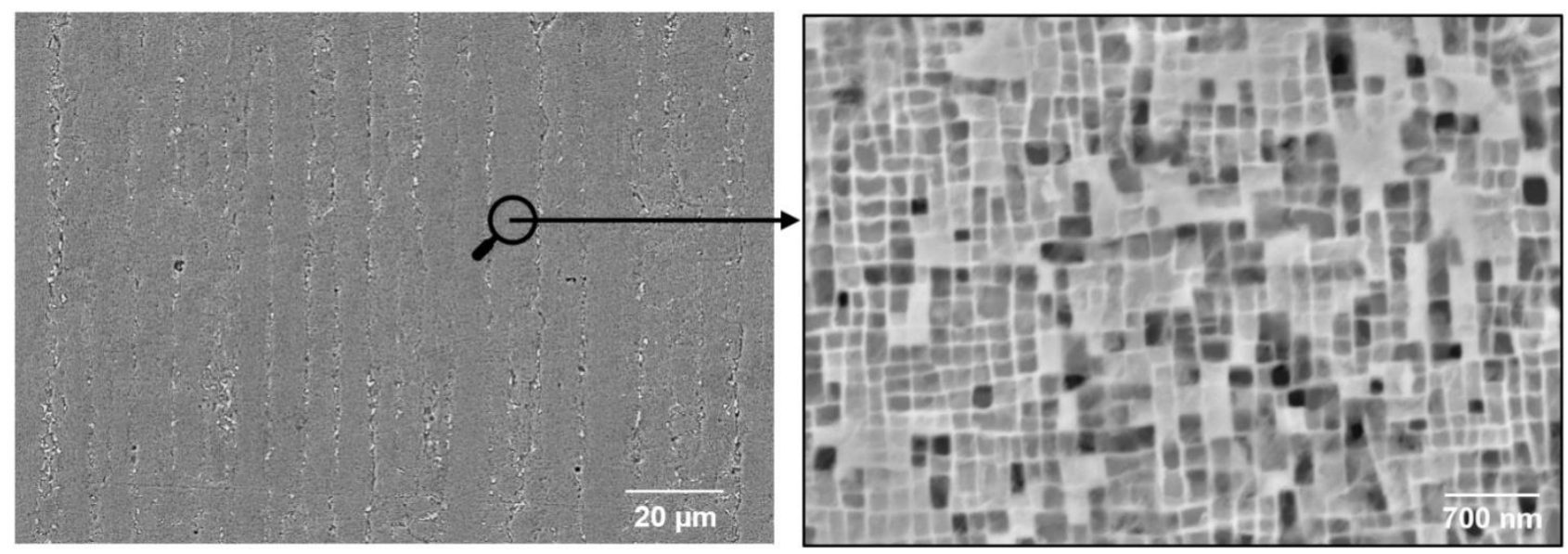

Figure 2 SEM images of the $\gamma / \gamma^{\prime}$ microstructure after SLM

$\mathrm{Nb}$ and Mo carbides are isolated along the boundaries of the $\mathrm{y}^{\prime}$ - phase cells. The presence of carbides of alloying elements improves the properties of heat-resistant alloys at temperatures above the solubility limit of the intermetallic y' - phase (Figure 3). However, at the same time, their presence leads to the formation of micropores of shrinkage origin.

A significant decrease in the volume content of the $\mathrm{y}^{\prime}$ - phase in the matrix is observed after heat treatment (Figure 3 a). Also, the $y^{\prime}$ - phase particles are enlarging and change their shape (Figure $\mathbf{3} \mathbf{b}$ ).
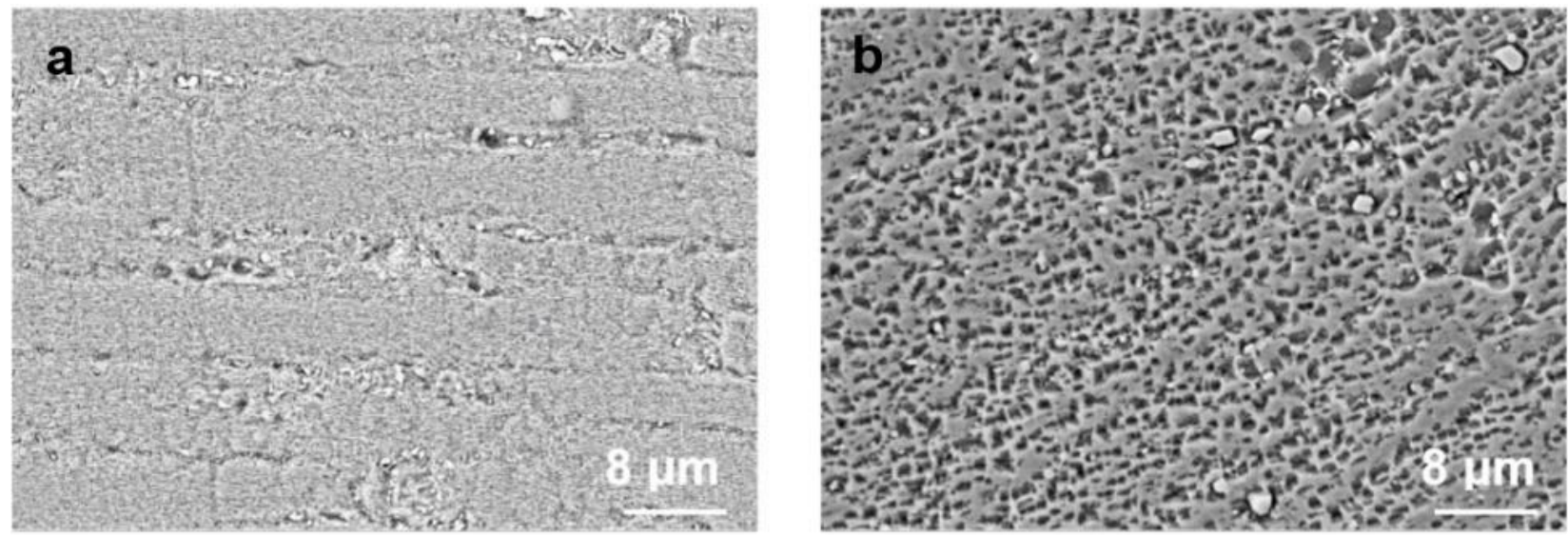

Figure 3 SEM images of the $\gamma / \gamma^{\prime}$ microstructure: a) after SLM; b) after heat treatment

Figure 4 shows the phase composition of the sample before and after heat treatment. From the XRD results, it follows that heat treatment leads to the release of $\mathrm{TaC}$ and WC. It is possible that the formation of carbides is due to the decomposition of a supersaturated solid solution of carbon in the Ni lattice. The detailed diffractogram of the sample examined before heat treatment shows that the separation of the $y$ and $y^{\prime}$ phases is observed in the region of 750 . The crystal lattice parameter of the $y$-phase is $a=0.3589 \mathrm{~nm}$, and the $\gamma^{\prime}$ phase is $a=0.3579 \mathrm{~nm}$. The misfit value $\Delta a=\left(a y-a y^{\prime}\right) /$ ay' for the sample before heat treatment was 0.003 .

Peak separation in the sample was not observed after heat treatment, which can be caused by the alignment of the lattice parameters of the $y$ and $y^{\prime}$ phases during heat treatment. The alignment of the parameters is perhaps due to a decrease in the lattice parameter of the $\mathrm{Y}$ - solid solution, caused by the release of carbides of alloying elements that the most increase the lattice period of the $\mathrm{Y}$ - solid solution, such as Ta, $\mathrm{W}$, and others. Thus, a decrease in the volume fraction of $\gamma^{\prime}$ - phase cells can be associated with a change in the crystal lattice parameter and a change in the chemical composition of the phases. 
Sample's structure is characterized by a strong texture. The strong (110) peak of sample 1 indicates that the crystallites are preferably (110)-oriented along the surface normal. The orientation of the crystallites along the direction perpendicular to the plane (001) in sample 2 is observed, the March-Dallas ratio was 0.35 .

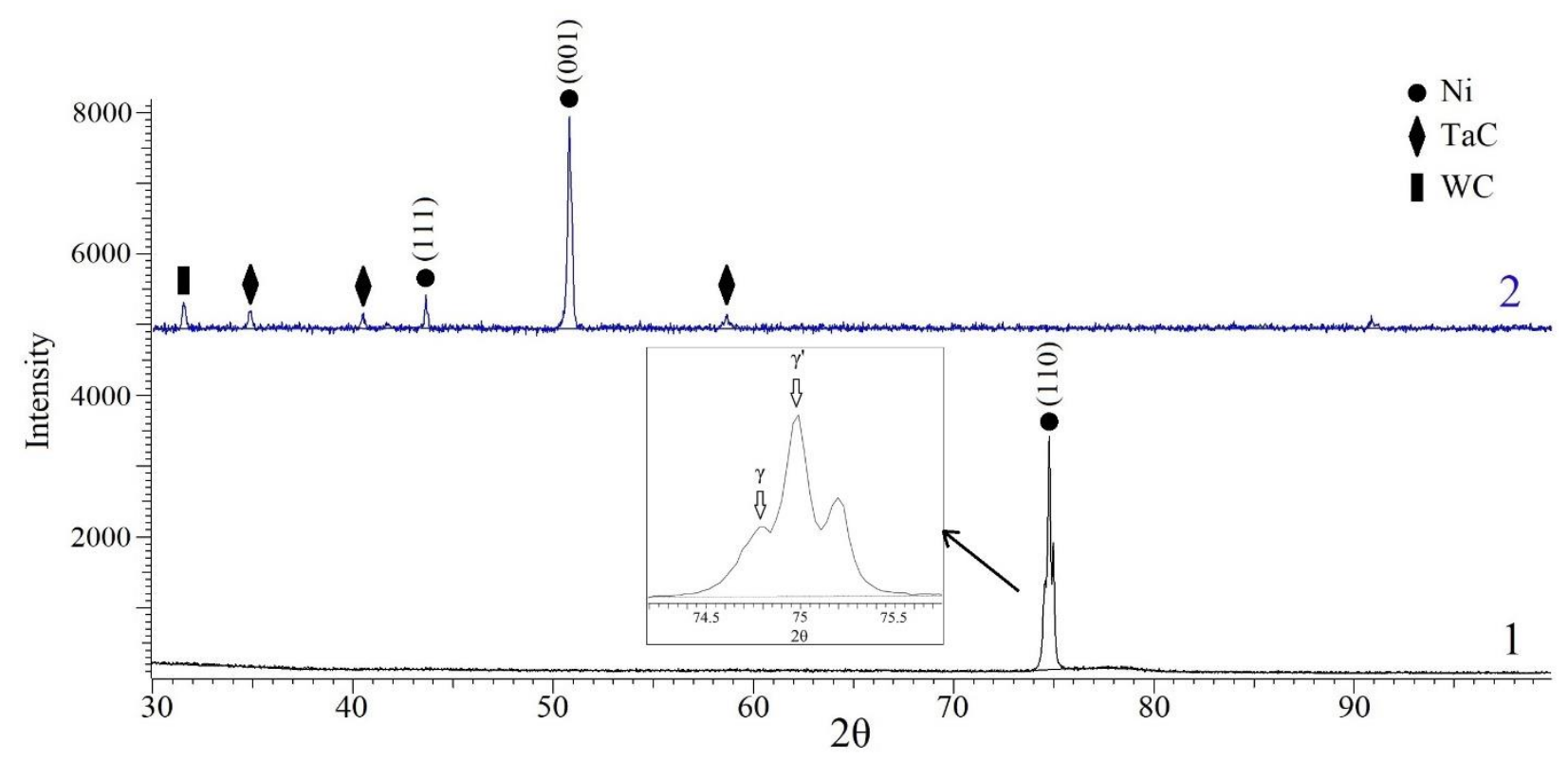

Figure 4 XRD pattern of the nickel-based superalloy samples

\section{CONCLUSION}

In this article, the influence of heat treatment on the structure and phase characteristics of a sample made by selective laser melting from a heat-resistant nickel alloy powder in the working chamber of the SLM installation was considered. It was found that during the heat treatment process in the machine, there is a significant decrease in the volume content of the $Y^{\prime}$ - phase in the $Y$ - solid solution. Moreover, the $Y^{\prime}$ - phase particles are enlarging and change their shape. This phenomenon can be explained by a change in they- solid solution and $y^{\prime}$ - phase lattices caused by the alignment of the - solid solution and $y^{\prime}$ - phase cells crystal latticesperiodsas a result of a change in the chemical composition of the phases. This alignment can occur due to the release of $\mathrm{TaC}$ and $\mathrm{WC}$ carbides and, as a result, the depletion of the $\mathrm{Y}$ - solid solution by the alloying elements $\mathrm{Ta}$ and $\mathrm{W}$, which isthemostincreasethe lattice period of the $\mathrm{Y}$ - solid solution.

\section{ACKNOWLEDGEMENTS}

This research was supported by Russian Science Foundation grant (project No 19-79-30002).

\section{REFERENCES}

[1] RAZUMOV, N.G. et al. Investigation of additive manufacturing from the heat-resistant steel powder produced by recycling of the machining chips. Journal of Manufacturing Processes. 2021, vol. 64, pp. 1070-1076.

[2] POLOZOV, I. et al. Synthesis of Ti-5Al, Ti-6Al-7Nb, and Ti-22Al-25Nb alloys from elemental powders using powder-bed fusion additive manufacturing. Journal of Alloys and Compounds. 2018, vol. 763, pp. 436-445.

[3] GONCHAROV, I.S. et al. Synthesis of Nb-based powder alloy by mechanical alloying and plasma spheroidization processes for additive manufacturing. Materials Letters. 2019, vol. 245, pp. 188-191.

[4] RAZUMOV, N.G. et al. Morphology of High-Strength Heat-Resistant Steel Powder for Machines for Additive Production from Shavings. Metal Science and Heat Treatment. 2019, vol. 60, no. 11-12, pp. 710-714. 
[5] GISARIO, A. et al. Metal additive manufacturing in the commercial aviation industry: A review. Journal of Manufacturing Systems. 2019, vol. 53, pp. 124-149.

[6] HUANG, R. et al. Energy and emissions saving potential of additive manufacturing: the case of lightweight aircraft components. Journal of Cleaner Production. 2016, vol. 135, pp. 1559-1570.

[7] GASSER, A. et al. Laser additive manufacturing: Laser Metal Deposition (LMD) and Selective Laser Melting (SLM) in turbo-engine applications. Laser Technik Journal. [online]. 2010, pp. 58-63. Available from: https://doi.org/10.1002/latj.201090029.

[8] ROMERO, A., DARLI RODRIGUES, V. How additive manufacturing improves product lifecycle management and supply chain management in the aviation sector? IFIP International Conference on Product Lifecycle Management. Springer, Cham, 2015.

[9] MOOSBRUGGER, V., et al. Progress in burner design using additive manufacturing with a monolithic approach and added features. In: ASME Turbo Expo 2019: Turbomachinery Technical Conference and Exposition. American Society of Mechanical Engineers Digital Collection, 2019. APA

[10] CHAUVET, E., et al. Producing Ni-base superalloys single crystal by selective electron beam melting. Scripta Materialia. 2018, vol. 152, pp. 15-19.

[11] JIA, QI., GU, D. Selective laser melting additive manufacturing of Inconel 718 superalloy parts: Densification, microstructure and properties. Journal of Alloys and Compounds. 2014, vol. 585, pp. 713-721.

[12] KARIA, M.C., POPAT, M.A., SANGANI, K.B. Selective laser melting of Inconel super alloy-a review. AIP Conference Proceedings. AIP Publishing LLC. 2017, vol. 1859, no. 1.

[13] WANG, X., GONG, X., CHOU, K. Review on powder-bed laser additive manufacturing of Inconel 718 parts. Proceedings of the Institution of Mechanical Engineers, Part B: Journal of Engineering Manufacture. 2017, vol. 231, no. 11, pp. 1890-1903

[14] POPOVICH, V.A., BORISOV, E.V., SUFIYAROV, V.S. et al. Tailoringthe properties in functionally graded alloy Inconel 718 using additive technologies. Met Sci Heat Treat. 2019, vol. 60, pp. 701-709.

[15] XU, J. et al. The initiation and propagation mechanism of the overlapping zone cracking during laser solid forming of IN-738LC superalloy. Journal of Alloys and Compounds. 2018, vol. 749, pp. 859-870.

[16] BORISOV, E. V. et al. Selective laser melting of Inconel 718 under high laser power. Materials Today: Proceedings. 2020, vol. 30, pp. 784-788.

[17] POLOZOV, I. et al. Microstructure, densification, and mechanical properties of titanium intermetallic alloy manufactured by laser powder bed fusion additive manufacturing with high-temperature preheating using gas atomized and mechanically alloyed plasma spheroidized powders. Additive Manufacturing. 2020, vol. 34, pp. 101374.

[18] BORISOV, E. et al. Cracks formation in nickel-based single crystal alloy manufactured by selective laser melting. In: Proceedings of the 29th International Conference on Metallurgy and Materials, Conference Proceedings (METAL 2020). TANGER Ltd., 2020, pp. 875-879. 